J. Lake Sci. (湖泊科学), 2006, 18(6):605-614

http:// www. jlakes. org. E-mail: jlakes@ niglas. ac.cn

(c) 2006 by Journal of Lake Sciences

\title{
全新世镜泊湖粒度特征记录的该地区古降水变化历史"
}

\author{
侯新花 ${ }^{1,2}$, 吴艳宏 ${ }^{1}$, 杨丽原 ${ }^{3}$ \\ (1: 中国科学院南京地理与湖泊研究所,南京 210008) \\ (2: 中国科学院研究生院,北京 100049) \\ (3: 济南大学, 济南 250022)
}

\begin{abstract}
摘 要: 在湖泊沉积与环境演变研究中, 粒度参数通常用来反映湖泊水动力条件的变化, 进而反映湖面波动状况以及湖区 环境有效湿度的变化. 镜泊湖 JPH-1 钻孔沉积物粒度分析表明: 全新世以来镜泊湖沉积物粒度的变化呈现明显的粗细交 替变化的规律性. 结合 ${ }^{14} \mathrm{C}$ 测年,镜泊湖沉积物粒度特征有效地指示了历史时期镜泊湖水动力变化的情况,进而揭示了该 地区古降水的变化历史. $9300-8540 \mathrm{cal} \mathrm{aBP}$, 是一个降水较少的偏干旱时期; $8540-6350 \mathrm{cal} \mathrm{aBP}$,降水颇丰的湿润时期; $6350-3120 \mathrm{cal} \mathrm{aBP}$,气候波动频繁,前期 ( $6350-4800 \mathrm{cal} \mathrm{aBP}$ ) 由湿润向干旱过渡,后期 (4800-3120 cal aBP 左右) 又由干 旱转向湿润,3120-1580 cal aBP,降水较多,气候湿润; $1580 \mathrm{cal} \mathrm{aBP}$ 至今,降水变化波动剧烈,这阶段粒度特征的变化除了 与降水的自然变化有关外, 还与人类活动的剧烈影响有关系. 湖区周围人类活动破坏了原始植被, 大量地表裸露, 降水冲 刷地表作用明显增大,陆源物质被携带入湖,粗颗粒含量显著增多.
\end{abstract}

关键词 : 镜泊湖; 沉积物粒度; 水动力;古降水

\section{The paleo-precipitation history recorded by the characteristics of grain-size of Lake Jingpo during Holocene}

HOU Xinhua ${ }^{1,2}$, WU Yanhong ${ }^{1} \&$ YANG Liyuan ${ }^{3}$

(1: Nanjing Institute of Geography and Limnology, Chinese Academy of Sciences, Nanjing 210008, P. R. China)

(2: Graduate School, Chinese Academy of Sciences, Beijing 100039 P. R. China)

(3: Jinan University, Jinan 250022, P. R. China)

\begin{abstract}
Grain-size composition of lacustrine sediment is a powerful indicator to water impetus change and humid variation in the history. Based on the analyses on the grain-size composition characteristics of JPH-1 core , from Lake Jingpo, northeastern of China, combined with ${ }^{14} \mathrm{C}$ age sequence, the Holocene history of paleo-precipitation changes in this region can be concluded as below: (1) $9300-8540$ cal aBP was a relatively dry period accompanied with less precipitation. (2) $8540-6350 \mathrm{cal}$ aBP was a high lake level period, when the precipitation was relatively abundanto. (3) $6350-4800 \mathrm{cal} \mathrm{aBP,} \mathrm{the} \mathrm{climate} \mathrm{became} \mathrm{drought} \mathrm{gradually.} \mathrm{(4)} 4800-3120 \mathrm{cal} \mathrm{aBP}$, the climate changed wet again. (5) $3120-1580 \mathrm{cal}$ aBP was a relatively stable period maintained a high lake level with abundant precipitation. (6) $1580 \mathrm{cal}$ aBP-present, it was an another climatically oscillation period in which the precipitation has been changing frequently. In recent centuries, the human activities, such as clearing the forest, destroying the original vegetation in lake watershed resulted in massive exposure of land surface, remarkable increase of erosion and more terrestrial materiel carried into lake. Therefore, the portion of coarser particles increased markedly.
\end{abstract}

Keyword: Lake Jingpo; grain-size; water impetus;Paleo-precipitation

在湖泊沉积与环境演变研究中, 沉积物的多种理化性质都可以作为环境变化的代用指标, 而粒度作为

* 中国科学院南京地理与湖泊研究所知识创新工程特别资助项目. 2005-12-30 收稿; 2006-04-26 收修改稿. 侯 新花,女,1980 生,硕士研究生. E-mail: hxj5198@ sina. com. 
一个物理指标, 因其简单、快速、经济、基本不受生物扰动、早期成岩作用的改造等影响, 能够敏感的记录当 时气候的变化情况, 可以直接反映沉积环境水动力条件, 从而受到广泛重视且应用相当广泛, 在深海沉积 物、黄土沉积物、湖泊沉积物研究中应用都比较成功 ${ }^{[1-15]}$. 早在八十年代, 就有科学家将粒度用于封闭湖泊 水位变化的研究 ${ }^{[3]}$. 一般的认为,粗粒沉积物指示湖泊收缩、湖水较浅的干旱气候期; 细粒沉积物指示湖泊 扩张、湖水较深的湿润气候期 ${ }^{[3-15]}$, 然而沉积物粒度特征在不同时间分辨率的研究中有不同的环境指示意 义, 上述的研究结果仅适于对封闭湖泊的长时间尺度、低分辨率 (千年、百年) 研究中 ${ }^{[4,6]}$, 而在高分辨率的 研究中, 当湖面相对稳定时, 较为丰沛的降水, 使得地表径流增强, 人湖水流搬运能力较强, 容易带人成分 较粗的陆源碎屑颗粒物质 ${ }^{[6-8]}$, 如此一来, 粗粒沉积物指示降雨量较大的湿润期, 细粒沉积物指示降雨量 较小的干旱期. 粒度特征的变化在开口湖泊中的指示意义又不同于封闭湖泊,在开口湖泊中,沉积物粒度的 粗细指示了人湖水流的强度、湖泊输人水量的相对大小, 在一定程度上反映湖区降水的变化, 指示有效湿度 [4]. 由此可见,粒度指标在应用于湖泊环境变化研究中具有其复杂性,利用湖泊沉积物的粒度变化反映湖 面的波动以及古气候的干湿变化不仅需要综合分析沉积物不同粒级的组成及变化特征,还要结合湖泊本身 的性质及其地理背景等情况加以综合判识. 本文旨在通过镜泊湖全新世以来的沉积物粒度的变化特征, 探 讨镜泊湖全新世沉积环境的变化, 由此反演该地区该时段的古降水变化的历史, 探讨全新世气候变化的不 稳定性特征 ${ }^{[16-18]}$.

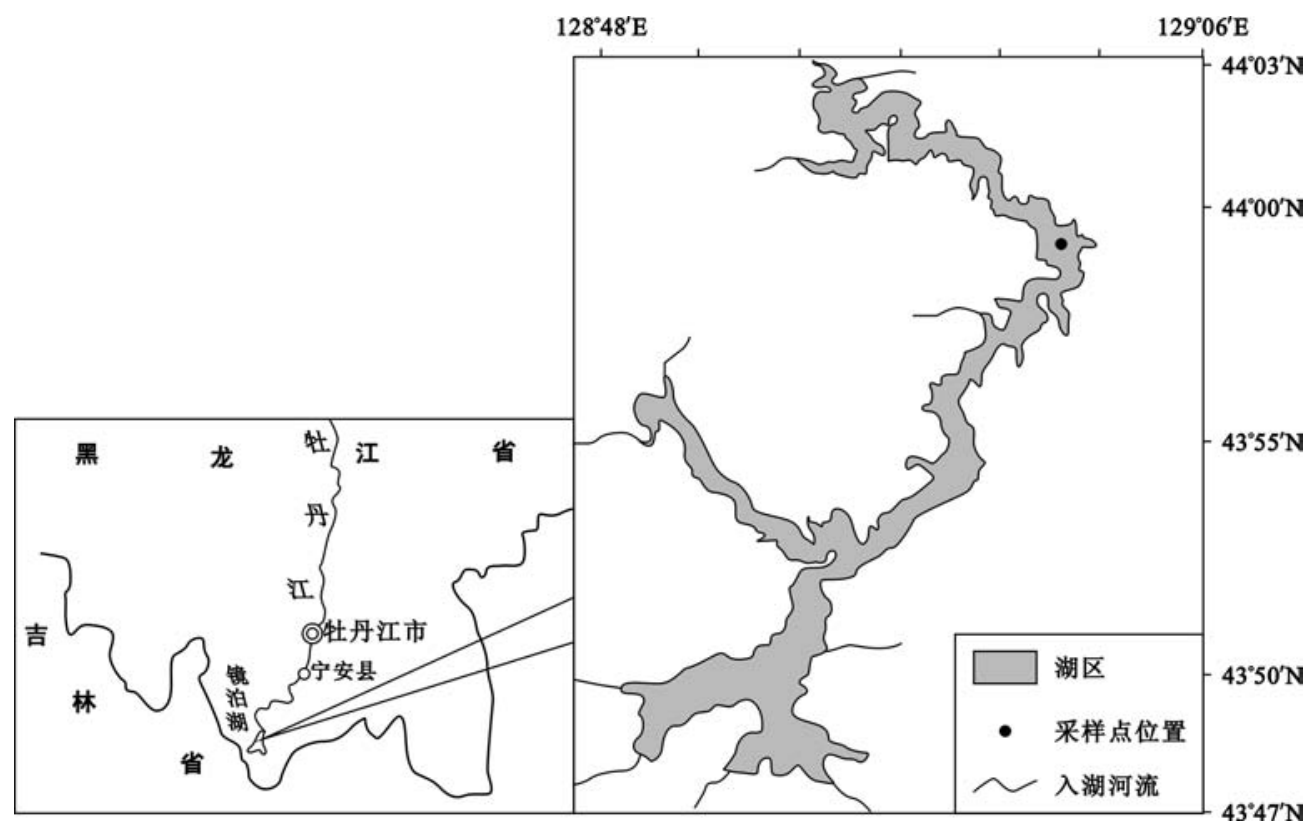

图 1 JPH-1 孔位置

Fig. 1 Location of JPH-1 core

\section{1 区域地质概况及研究材料}

镜泊湖 $\left(43^{\circ} 46^{\prime}-44^{\circ} 03^{\prime} \mathrm{N}, 128^{\circ} 27^{\prime}-129^{\circ} 03^{\prime} \mathrm{E}\right)$ 位于黑龙江省宁安县, 地处牡丹江上游段水域, 是大约 一万年之前火山喷发雍塞牡丹江而成的高山熔岩堰塞湖. 南北长近 $50 \mathrm{~km}$, 最宽处 $9 \mathrm{~km}$, 全湖总面积 90.3 $\mathrm{km}^{2}$, 湖面海拔 $350 \mathrm{~m}$, 最大水深 $62 \mathrm{~m}$, 平均水深 $40 \mathrm{~m}$. 湖水主要依赖地表径流和湖面降水补给, 人湖大小河 流 30 余条, 其中牡丹江人湖水量最大, 尔站河、石头甸子河、松沟河等众多支流的年人湖量为次, 镜泊湖水 位变化除受补给变化影响外,还与出水口的排水量有关,地表出水口为北部的瀑布,另外,1939 年在镜泊湖 出口处建设水电站 ${ }^{[19]}$, 为保证水位落差, 对出水量进行了人为控制, 自此镜泊湖水位保持相对稳定. 湖区属 温带湿润气候, 由于湖区的下垫面的影响, 使湖区的气候出现偏冷偏湿的特点. 年均气温 $3.5{ }^{\circ} \mathrm{C}$, 年日照时 
数 $1903-2160.8 \mathrm{~h}$, 多年平均无霜期 $135 \mathrm{~d}$, 年降水量 $528.3 \mathrm{~mm}$, 最大年降水量 $641.3 \mathrm{~mm}$. 湖区盛行西 南风[20,21].

2003 年 7 月,利用水上平台和活塞采样器, 在镜泊湖的东北部采得长度为 $890 \mathrm{~cm}$ 的沉积物柱状样品 ( JPH - 1) , 采样位置位于 $43^{\circ} 59^{\prime} 20.9^{\prime \prime} \mathrm{N}, 129^{\circ} 02^{\prime} 06.3^{\prime \prime} \mathrm{E}$ (图 1), 按 $1 \mathrm{~cm}$ 间隔采样进行环境指标分析.

\section{2 实验分析方法}

JPH-1 孔的粒度分析采用 MALVERN 公司生产的 MASTERSIZER 2000 激光粒度仪完成. 首先对样品进 行前期处理,利用 $10-30 \mathrm{ml}$ 过氧化氢去除样品中的有机质, 然后用 5\% 的盐酸去除无机碳 (主要是钙质胶 结物 ), 加人六偏磷酸钠震荡 $15 \mathrm{~min}$. MASTERSIZER2000 激光粒度仪测量粒径范围为 $0.020-2000.000 \mu \mathrm{m}$, 可以保证获得完整的粒度分布曲线,重复测量误差小于 $\pm 1 \%$.

镜泊湖沉积物近代年龄的测定是利用 ${ }^{210} \mathrm{~Pb}$ 和 ${ }^{137} \mathrm{Cs}$ 方法, 取适量的样品在低温 $\left(<40{ }^{\circ} \mathrm{C}\right)$ 下烘干后, 称 重, 然后利用 EG \& G Ortec 公司生产的高纯锗探测器 (Ortec HPGe GWL) 与 Ortec919 型谱控制器构成的多 道 $\gamma$ 谱分析系统测定.

同时在 JPH - 1 孔的不同深度共采集了 8 个样品用于 ${ }^{14} \mathrm{C}$ 年代测量, 其中 3 个样品在波兰 Poznan ${ }^{14} \mathrm{C}$ 年 代实验室用加速器质谱 (AMS) 的方法测定, 另 5 个在湖泊沉积与环境重点实验室用液体闪炼计数的方法 ( LSC) 测定,所用原料均为样品所含总有机碳. 对所获年代数据分别进行 “碳库效应”校正和日历年龄校正, 日历年龄校正用 OxCal3.5 校正程序完成, 参照 INTCAL 98 校正数据库,采用 $2 \sigma$ 校正结果的中值年龄.

\section{3 结果}

\section{1 剖面年代序列的建立}

$3.1 .1{ }^{137} \mathrm{Cs}$ 和 ${ }^{210} \mathrm{~Pb}$ 测年 镜泊湖沉积物近代年龄测定是利 用 $\mathrm{JPH}-3$ 孔 $(70 \mathrm{~cm})$ 岩芯进行 ${ }^{137} \mathrm{Cs}$ 和 ${ }^{210} \mathrm{~Pb}$ 测年. ${ }^{137} \mathrm{Cs}$ 首次 检出在 $26 \mathrm{~cm}$ 处, 1963 年北半球 ${ }^{137} \mathrm{Cs}$ 时标出现在 $19 \mathrm{~cm}$, 其余 时标不明确. ${ }^{210} \mathrm{~Pb}$ 波动幅度较大, 明显不呈指数分布, 因此采 用 ${ }^{210} \mathrm{~Pb}$ 的 CRS 模式计算各时段的沉积速率. 据计算, $19 \mathrm{~cm}$ 处对应于 1960 年, 与 ${ }^{137} \mathrm{Cs}$ 较接近, 但仍可看出 ${ }^{137} \mathrm{Cs}$ 发生了垂 向迁移, 因而 ${ }^{137} \mathrm{Cs}$ 首次检出位置偏低. 因此镜泊湖近代沉积 物年代序列采用 ${ }^{210} \mathrm{~Pb}$ 的 CRS 模式计算获得 (图 2).

$3.1 .2{ }^{14} \mathrm{C}$ 年代测试 首先对 JPH-1 孔 $(890 \mathrm{~cm})$ 不同深度的 6 个样品分别进行了 ${ }^{14} \mathrm{C}$ 年代测定, 结果显示, 镜泊湖 ${ }^{14} \mathrm{C}$ 测年 可能受到了 “碳库效应” 的影响, 为此, 在钻孔上部补测了 2 个样品进行 LSC 测年. 其中, 由于 LSC 测年要求样品量较大, 采样深度的跨度较大, 导致测年精度偏低, 表层 ${ }^{14} \mathrm{C}$ 测年样品 所测结果表现为现代碳, 没有获得理想中的“碳库效应”年 代,这并不说明“碳库效应”不存在, 只是由于采样精度,未能

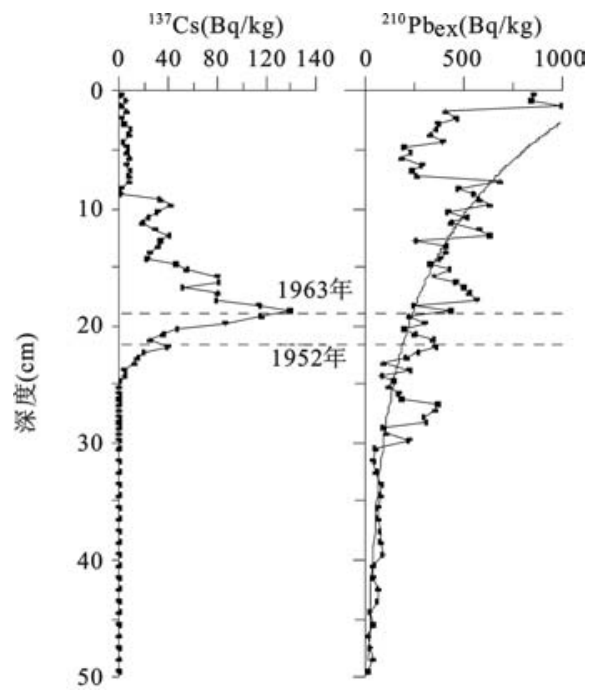

图 $2 \mathrm{JPH}-3$ 孔 ${ }^{210} \mathrm{~Pb} 、{ }^{137} \mathrm{Cs}$ 变化曲线 获得 “碳库效应” 年代. 我们采用另外的 7 个年代数据进行进 Fig. 2 Variations of ${ }^{210} \mathrm{Pbex},{ }^{137} \mathrm{Cs}$ of JPH-3 core 一步校正为日历年龄.

这 7 个 $^{14} \mathrm{C}$ 年代数据呈现很好的线性相关,表明在较长时间尺度上, 镜泊湖的物源稳定, 沉积速率变化 不大,另一方面，“碳库效应”的影响在历史上应该是比较连续、稳定的. 对照 ${ }^{210} \mathrm{PbCRS}$ 测年结果, $1950 \mathrm{AD}$ 对 应于 $22 \mathrm{~cm}$, 因此将这一深度的 ${ }^{14} \mathrm{C}$ 年代假定为 $0 \mathrm{cal} \mathrm{aBP}$, 同时根据其他 7 个 $^{14} \mathrm{C}$ 年代数据回归获取的年龄与 深度的关系式：

$$
X=10.776 Y-12.625 \quad R^{2}=0.9966
$$

其中, $X$ 代表某一深度的年龄, $Y$ 代表深度. 获得这一深度约为 $225 \mathrm{cal} \mathrm{aBP}$,因此将 $225 \mathrm{a}$ 作为镜泊湖的“碳库 效应”年代,测定及校正结果如表 1 和图 3 . 
表 1 镜泊湖 ${ }^{14} \mathrm{C}$ 年龄测定和校正结果

Tab. 1 The determined and calibrated ${ }^{14} \mathrm{C}$ ages of Lake Jingpo

\begin{tabular}{|c|c|c|c|c|c|c|c|c|c|}
\hline 样号 & $\begin{array}{l}\text { 深度 } \\
(\mathrm{cm})\end{array}$ & 实验室 & 方法 & $\begin{array}{l}{ }^{14} \mathrm{C} \text { 年龄 } \\
(\mathrm{cal} \mathrm{aBP})(\end{array}$ & $\begin{array}{c}\text { 校正年龄 } \\
\text { 2sigma cal aBP }\end{array}$ & $\begin{array}{l}\text { 中值年龄 } \\
\text { (cal aBP) }\end{array}$ & $\begin{array}{l}\text { 平均年龄 } \\
(\mathrm{cal} \mathrm{aBP})\end{array}$ & $\begin{array}{c}\text { 误差 e } \\
(+/-a)\end{array}$ & $\begin{array}{c}\text { 二次校正 } \\
\text { 年龄 } \\
(\mathrm{cal} \mathrm{aBP})\end{array}$ \\
\hline JPH-1 & 126 & 波兰 & $\mathrm{AMS}^{1)}$ & $1442 \pm 35$ & $1408-1289$ & 1321 & 1349 & 60 & 1096 \\
\hline JPH-2 & $122-132$ & 中国 & $\mathrm{LSC}^{2)}$ & $1773 \pm 131$ & $1992-1391$ & 1706 & 1692 & 301 & 1481 \\
\hline JPH-3 & $314-328$ & 中国 & LSC & $2951 \pm 162$ & $3473-2751$ & 3128 & 3112 & 361 & 2903 \\
\hline JPH-4 & 317 & 波兰 & AMS & $3053 \pm 35$ & $3358-3083$ & 3297 & 3221 & 138 & 3072 \\
\hline JPH-5 & 508 & 波兰 & AMS & $4920 \pm 50$ & $5834-5588$ & 5624 & 5711 & 123 & 5399 \\
\hline JPH-6 & $881-887$ & 中国 & LSC & $8483 \pm 235$ & $10172-8995$ & 9511 & 9584 & 589 & 9286 \\
\hline JPH-7 & $70-83$ & 中国 & LSC & $806 \pm 134$ & $967-540$ & 724 & 754 & 213 & 499 \\
\hline
\end{tabular}

1) AMS, 加速器质谱方法测试; 2) LSC, 液体闪炼计数法测试

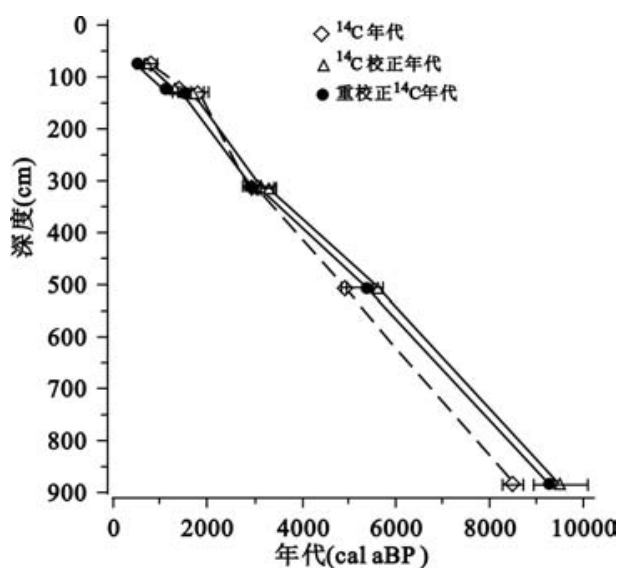

图 $3 \mathrm{JPH}-1$ 孔 ${ }^{14} \mathrm{C}$ 年龄测定和校正结果

在湖泊沉积中沉积介质是水,碎屑在水体中的 沉降遵循斯托克斯定律, 其细颗粒部分的沉积速率 是均匀的,一定厚度或质量的湖泊沉积物堆积所需 的数据与其某一细颗粒粒级的含量成比例. 基于这 一认识, 产生了湖泊沉积年代序列序列的计算 模型 ${ }^{[22]}$ :

$$
T_{m}=T_{1}+\left(S_{m} A_{m} / \sum S_{i} A_{i}\right) \times\left(T_{2}-T_{1}\right)
$$

式中 $T_{m}$ 为 $i$ 为 $m$ 样号的底界年龄, $T_{1}$ 为 $i=1$ 样号的已知顶界年龄, $T_{2}$ 为 $i=n$ 样号的已知底界 年龄, $A_{i}$ 为 $i$ 样号的厚度, $S_{i}$ 为 $i$ 样号的某种粒度 值的百分含量.

本文对 JPH-1 孔沉积物颗粒不同粒级含量应 用于模型进行调试, 结果显示, $<8 \mu \mathrm{m}$ 的颗粒组分 最适宜于 JPH-1 孔的年龄计算, 由此计算获得 JPH1 孔 $22 \mathrm{~cm}$ 以下年代序列, $22 \mathrm{~cm}$ 以上年龄根据 ${ }^{210}$

Fig. 3 The determined and calibrated ${ }^{14} \mathrm{C}$ age of JPH-1 core

PbCRS 结果获得,如图 4 所示. 由于下部的压实作用,上部和下部的累积速率明显不同.

\section{2 剖面的粒度分布特征}

粒度分析结果表明,JPH-1 孔沉积物粒径总体的变化趋势为粗细交替变化. 粒径主要分布在 $0-64 \mu \mathrm{m}$ 之间,平均粒径变化于 5.3-33.4 $\mu \mathrm{m}$ 区间, 中值粒径变化于 $3.5-7.4 \mu \mathrm{m}$, 其中粘土组分 $(<4 \mu \mathrm{m})^{[13]}$ $8.2 \%-60.5 \%$, 粉砂组分占到 $39.5 \%-81.4 \%$, 尤以细粉砂为主, 细粉砂 $(4-16 \mu \mathrm{m})$ 为 $29.4 \%-62.2 \%$, 中粉砂 $(16-32 \mu \mathrm{m}) 1.9 \%-23.1 \%$, 而粗粉砂 (32-64 $\mu \mathrm{m}$ ) 和砂 ( > $64 \mu \mathrm{m}$ ) 除了个别取样点大于 $15 \%$ 以 外, 其他的均在 $15 \%$ 以内 (图 5). 总之, JPH-1 孔沉积物颗粒整体属于粉砂一一粘土质粉砂, 以细颗粒为主, 反映了历史时期的镜泊湖水位较高. 其中, 粒径 4-32 $\mu \mathrm{m}$ 的颗粒与中值粒径在剖面垂向分布的趋势相同, 两者与 $<4 \mu \mathrm{m}$ 和 $>32 \mu \mathrm{m}$ 的颗粒含量在剖面的垂向分布趋势呈镜向变化.

将原始数据根据福克和沃德公式换算为以 $\Phi$ 为单位的数值,有利于统计粒度的分选系数等参数,并且 画出典型阶段的粒度频率曲线,这些指标对于研究水动力状况有明确的意义. 分选系数表示沉积物颗粒的 分选程度, 从另一个侧面反映沉积物介质的动能状况, 分选系数大表示分选性差, 反映水动力强, 镜泊湖粒 度的分选系数的变化范围为 $1.24 \Phi-2.88 \Phi$, 根据福克和沃德 ${ }^{[23]}$, 分选性由较差到差, 反映出镜泊湖水动力 相对较强,说明镜泊湖沉积环境受周围入湖河流的影响较大.

沉积物的频率曲线特征是判断沉积作用形式的重要手段之一, 频率曲线的峰态变化常反映了沉积作 用形式的变化, 为此我们对沉积物几个典型阶段的的粒度频率曲线特征表现进行分析: 岩心 $813-889 \mathrm{~cm}$ 
沉积物粒度频率曲线基本表现 $\mathrm{f}$ 曲线, $600-813 \mathrm{~cm}$ 表 现为 $\mathrm{e}$ 曲线, $451-600 \mathrm{~cm}$ 表现为 $\mathrm{d}$ 曲线, $451-311 \mathrm{~cm}$ 表现为 $\mathrm{c}$ 曲线,而 $311-164 \mathrm{~cm}$ 表现为 $\mathrm{b}$ 曲线, $0-164$ $\mathrm{cm}$ 表现为 $\mathrm{a}$ 曲线, 从图 6 中可以看出各典型阶段的频 率特征曲线均表现为较为对称的单峰态, 反映出物质 沉积前所受搬运营力性质单一, 主要受流水作用的 影响.

正态概率累计曲线是用粒度资料分析沉积环境 的常用方法, 镜泊湖概率累计曲线可以分为以下几种 情况 (图 7) 剖面的频率累计曲线多缺少推移质, 含量 很低, 起始粒径多在 $2 \Phi$ 附近. 概率累计曲线也反映了 镜泊湖物质沉积所受作用比较单一, 主要受水流沉积 的作用. $\mathrm{a} 、 \mathrm{~b} 、 \mathrm{e}$ 段曲线相似, 反映了比较相似的水动力 变化条件, 反映了水动力较强, 而 $\mathrm{c} 、 \mathrm{~d}$ 曲线反映了水动 力较弱且变化不稳定, $\mathrm{f}$ 曲线介于两类概率累计曲线 之间, 水动力条件中等.

\section{4 全新世镜泊湖沉积物粒度反映的该区的降 水历史}

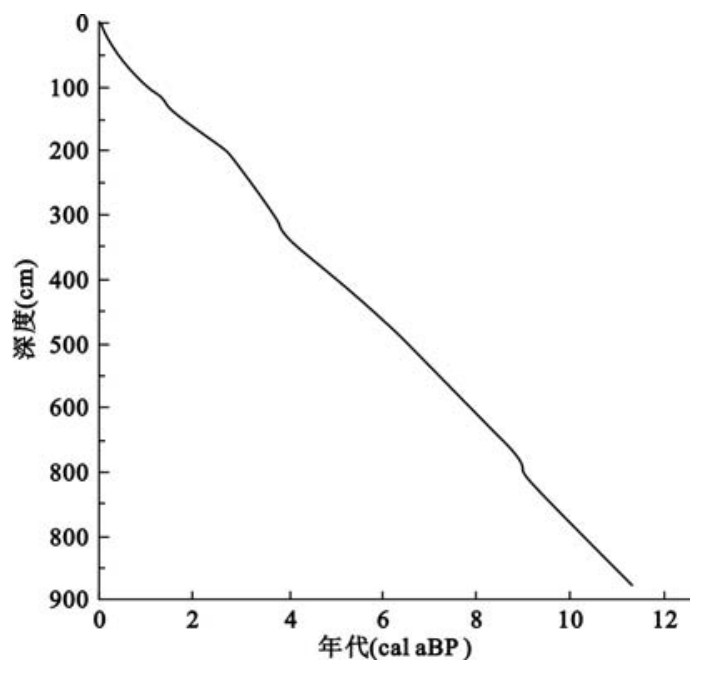

图 4 JPH-1 孔年代序列

Fig. 4 the time sequence of JPH-1 core

在封闭湖泊中,细颗粒和粗颗粒分别对应了高水位和低水位,粗颗粒的增加对应了气候干旱期. 而在本 研究区, 湖泊的范围及地理背景则是一个很重要的因素. 镜泊湖是一个开口湖泊,在湖北部的出口处,流水 深切于第四系玄武岩层中,形成一道宽 $40.0 \mathrm{~m}$, 落差 $12.0 \mathrm{~m}$ 的吊水楼瀑布, 当湖面水位达到溢出线 $350 \mathrm{~m}$ 时, 就会有湖水溢出,所以镜泊的湖面在历史时期保持在一个相对稳定的状态,在这里无法用湖泊水位的波 动来解释粒度的变化. 开口湖泊不同于封闭湖泊,这里也无法用封闭湖泊中粒度的变化机制来解释其指示 的气候变化情况. 镜泊湖处于湿润气候区, 在全新世时期, 总的来说是属于湿润的, 从图 6 中可以知道, 镜泊 湖颗粒物粒度频率曲线绝大部分为单峰, 它的沉积主要受水流作用的影响, 湖中的颗粒物质主要是由人湖 水流或降水冲刷作用携带而人的,在水动力较强的时候,细颗粒来不及沉积下来就随着出湖水流流走了, 而 粗颗粒却由于重力作用沉积下来, 而在水动力较弱的时候, 大部分细颗粒就沉积在湖中. 于是, 湖区降水量 的变化成为控制该湖沉积物粒度分布的重要因素,降水量的变化通过影响地表径流的强度决定了湖泊的陆 源颗粒物质的粗细和多少, 进而影响沉积物粒度. 降雨量大时湖区流域地表径流发育, 较强的水动力条件可 将较粗的陆源颗粒携带之湖泊并沉降,而细颗粒则随水流流走,粗颗粒含量增多; 相反,降雨量小时湖区流 域地表径流贫乏,较弱的水动力条件难以将粗颗粒陆源物质携带至湖泊,故沉积物粒径较小 ${ }^{[6,11,24]}$.

对粒度与气象资料的关系进行研究,可以明确气候状况对粒度的影响,得出粒度对气候环境变化的响 应模式,从而为用粒度变化恢复本区古环境演变找到基本的影响关系,通过对牡丹江站点 $1950-2000$ 年的 降水记录与镜泊湖的粒度资料进行对比,结果发现粗颗粒含量的变化与降水量的变化存在较好的正相关关 系,这也验证了在本区粗颗粒含量的增加意味着降水量增大、气候湿润的解释.

根据 JPH-1 孔粒度各参数曲线特征,并基于以上对粒度的古环境意义的分析, 镜泊湖地区 $9300 \mathrm{cal} \mathrm{aBP}$ 以来的沉积序列可以划分为以下几个阶段:

(1) 底部 $890-819 \mathrm{~cm}$ (约 $9300-8540 \mathrm{cal} \mathrm{aBP}$ ). 此时,镜泊湖地区处于全新世的早期. 从整体情况来看, 此阶段粒径处于序列中较为平均的状况. 4-32 $\mu \mathrm{m}$ 的颗粒百分含量处于整个剖面中较高的阶段,粒径 $>32$ $\mu \mathrm{m}$ 粗颗粒含量相对较少, 平均粒径较小, 分选系数在 1.5 左右, 分选性较差,这些表明该阶段内在中等水动 力条件下有较多的细颗粒, 反映出降水量少, 尤其是 $890-843 \mathrm{~cm}$ (约 $9300-8870 \mathrm{cal} \mathrm{aBP}$ ), 粗颗粒含量降 低, 水动力相对较弱, 总体来说气候比较干旱.

(2) $819-595 \mathrm{~cm}$ (约 $8540-6350 \mathrm{cal} \mathrm{aBP}$ ). 根据施雅风研究 ${ }^{[25]}$, 从这一时期开始该区进人全新世大暖 


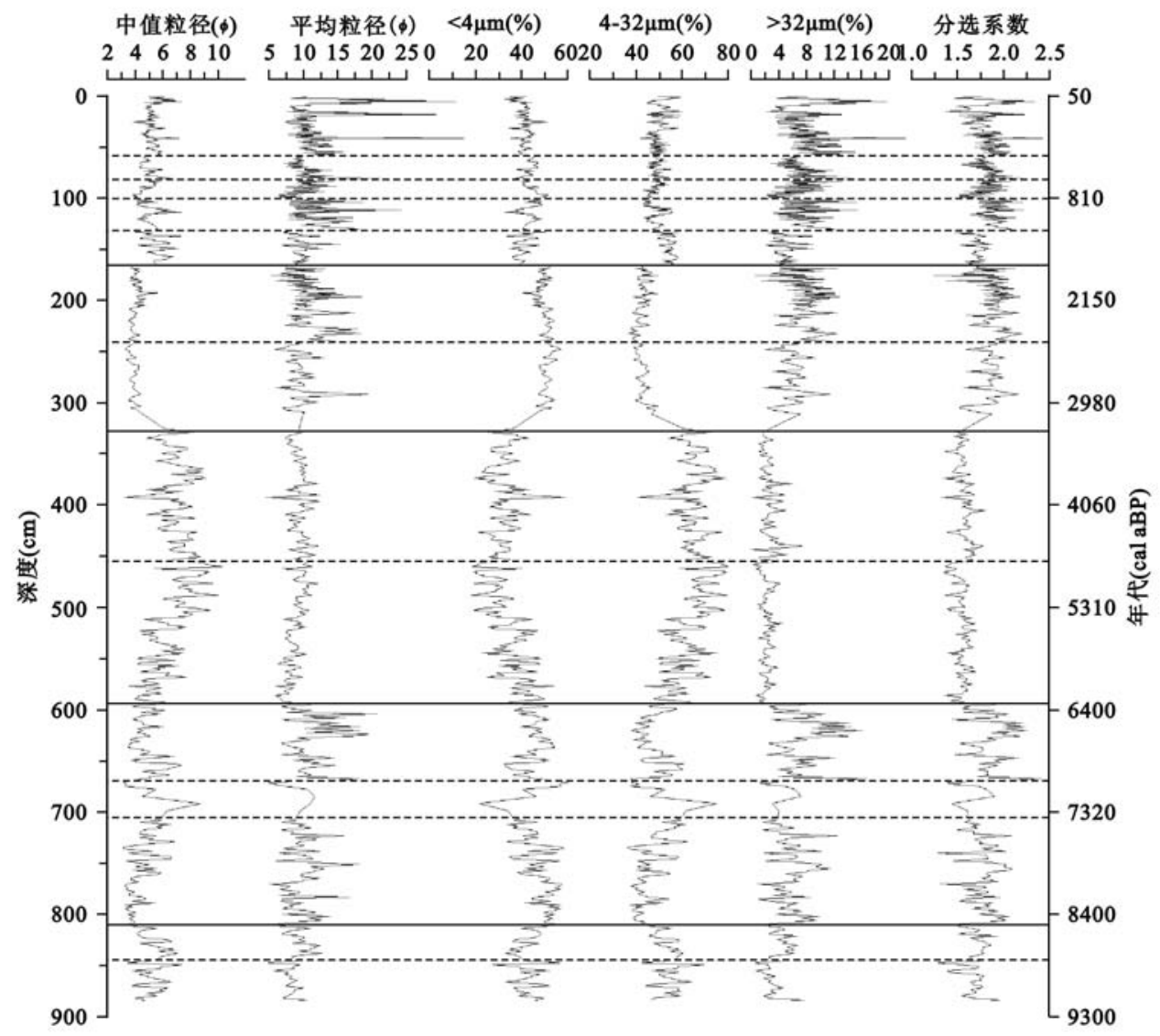

图 5 JPH-1 孔粒度分布图

Fig. 5 the distribution of grain - size of JPH-1 core

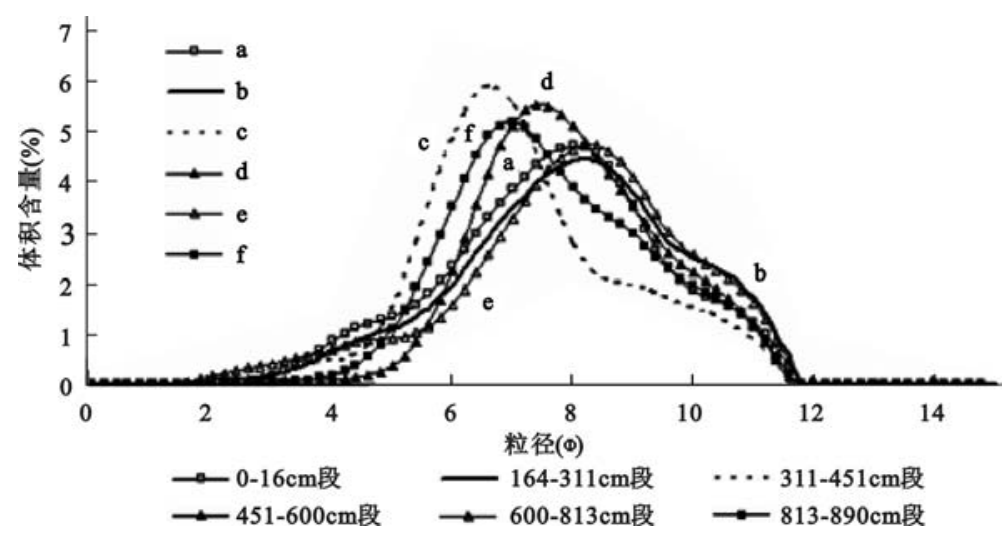

图 6 沉积物粒度频率曲线特征

Fig. 6 Frequency curve of sediment grain sizes 


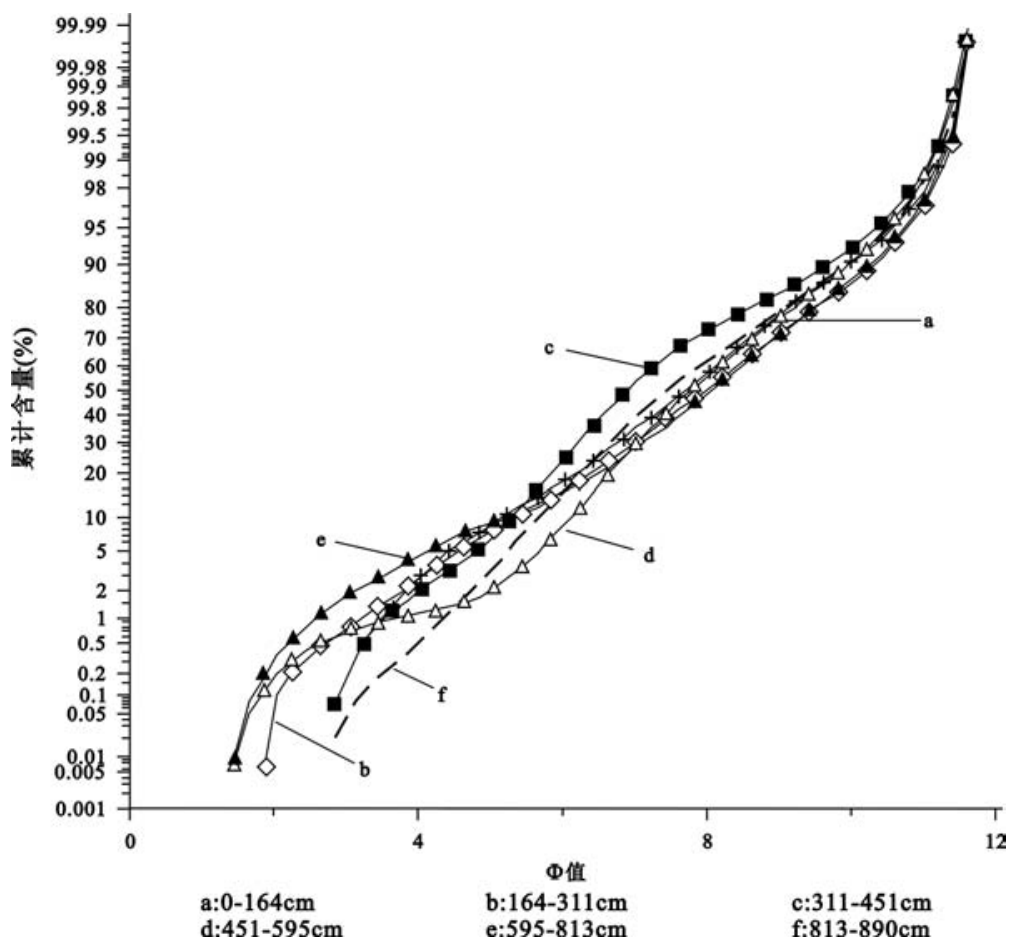

图 7 JPH-1 孔概率累计曲线特征

Fig. 7 Probability cumulative curve of of sediment grain sizes of JPH-1 core

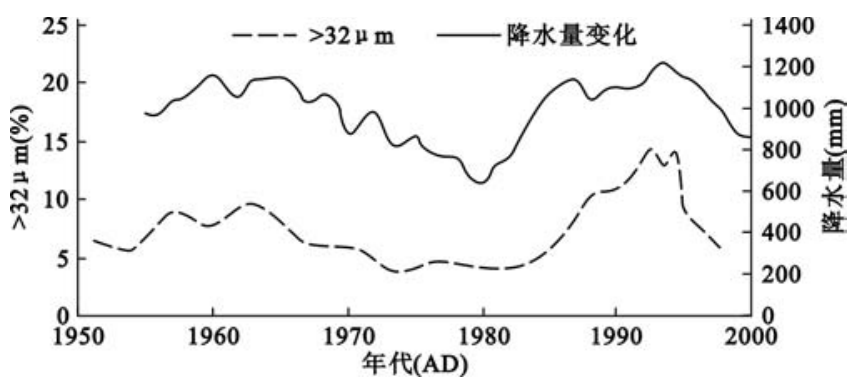

图 $8 \mathrm{JPH}-1$ 孔粗颗粒沉积物含量与降水量变化对比

Fig. 8 Comparison of coarse particle changes of JPH-1 core and precipitation

期. 中值粒径处于整个剖面的较低值, 平均粒径出现剧烈波动. 总体来看, 除了 $708-669 \mathrm{~cm}$ (约 $7370-7130$ $\mathrm{cal} \mathrm{aBP}$ ) 段,各粒级发生突变外, 其他时间各粒级颗粒含量均呈一定趋势的变化, $4-32 \mu \mathrm{m}$ 颗粒百分含量 减少, 而 $<4 \mu \mathrm{m}$ 的粘土组分和 $>32 \mu \mathrm{m}$ 的粗颗粒组分的百分含量均增大到整个剖面的较高值, 分选系数增 大到 2.2 ,分选性变差,水动力增强,表明该时期人湖水流增强,并形成较强的地表径流,携带部分陆源碎屑 物质人湖, 致使粗颗粒含量增加. 而由于湖面达到溢出线, 细颗粒随着出湖水流流走, 中细粉砂含量减少. 而 在 7370 - 7130 cal aBP 间出现了粒径突变, 4-32 $\mu \mathrm{m}$ 的颗粒含量在 $7350 \mathrm{cal} \mathrm{aBP}$ 左右开始急剧增加, 至 $7290 \mathrm{cal} \mathrm{aBP}$ 出现峰值, 而在 $7290-7130 \mathrm{cal} \mathrm{aBP}$ 间又降低, 在 $7190 \mathrm{cal} \mathrm{aBP}$ 左右出现最低峰值, 而 $>32 \mu \mathrm{m}$ 的粗颗粒含量和分选系数的变化与 $4-32 \mu \mathrm{m}$ 的颗粒含量变化相反,细颗粒的增加反映了湖泊向弱水流环 境的变化,而接下来的细颗粒的减少则表明湖泊又进人强水流环境, 粗颗粒的增加代表了较强的降水补给. 
总体看来该段时期内,湖区处于一个比较湿润的气候期内, 中间发生较短暂的干旱.

(3) $595-311 \mathrm{~cm}$ (约 $6350-3120 \mathrm{cal} \mathrm{aBP}$ ), 沉积颗粒主要以中细粉砂为主, 平均粒径和粒径 $>32 \mu \mathrm{m}$ 的 颗粒百分含量很小 $(<5 \%)$ 并且波动较小, 分选系数处于剖面的最低值段, 推测水动力条件较弱且变化不 大. 这一状况一直持续到 $3120 \mathrm{cal} \mathrm{aBP}$, 可能标志着该地区大暖期的结束. 提出大暖期一词的 Hafsten 认为, 大暖期终止于北方期的后段 (约 $3300 \mathrm{cal} \mathrm{aBP}$ ), 由于区域的差异,大暖期的终止时间在各地有所不同, 本文 认为,在该地区大暖期的终止时间是在约 $3100 \mathrm{cal} \mathrm{aBP}$. 这一阶段可划分为两个亚阶段:595-458 $\mathrm{cm}$ (约 $6350-4800 \mathrm{cal} \mathrm{aBP}$ ), 中值粒径和 4-32 $\mu \mathrm{m}$ 的中细粉砂显著增大,增至剖面最大值, $>32 \mu \mathrm{m}$ 的粗颗粒的 百分含量将至序列的最低阶段并保持相对稳定, 分选系数在 1.5 左右, 分选性由差转为较差, 反映出水动力 由强变弱,表征这段时间在继承了前阶段的暖湿特点的基础上湖区降水在逐步减少,气候逐渐向干旱过渡; $458-311 \mathrm{~cm}$ (约 $4800-3120 \mathrm{cal} \mathrm{aBP}$ ), 粒径变化与上一阶段恰好相反, 中值粒径和中细粉砂百分含量趋于减 小, $>32 \mu \mathrm{m}$ 的粗颗粒物质百分含量有所增加, 分选系数有所增大, 反映水动力有所增强, 降水缓慢增多, 气 候又由干早转向湿润.

(4)329-165 cm(约 3120 - $1580 \mathrm{cal} \mathrm{aBP}$ ), 进人全新世晚期, 期间中值粒径、粒径 $<4 \mu \mathrm{m} 、 4-32 \mu \mathrm{m}$ 的 颗粒物百分含量都较前期有一个大的变化, $<4 \mu \mathrm{m}$ 的粘土颗粒组分较前期显著增多, 中值粒径和中细粉砂 含量下降到剖面的较低值, 同时, $>32 \mu \mathrm{m}$ 的粗颗粒含量明显增加, 分选性变差, 反映这一时期湖区降水增 加, 地表径流增大, 水动力增强, 相对较多的粗颗粒物质被携带人湖. 尤其是在约 $244-165 \mathrm{~cm}$ (约 $2530-$ $1580 \mathrm{cal} \mathrm{aBP}$ ) 期间, 粗颗粒含量波动幅度增大, 而且分选系数也增大到 2 , 分选性降低, 水动力增加, 一方面 是因为降水增多,另一方面可能是由于人类活动的出现所致.

(5) $165-0 \mathrm{~cm}$ (约 $1580 \mathrm{cal} \mathrm{aBP}$ - 至今), 在 $165-133 \mathrm{~cm}$ (约 $1580-1130 \mathrm{cal} \mathrm{aBP}$ ), 粒径 $<4 \mu \mathrm{m}$ 的粘土 颗粒百分含量明显降低,而中值粒径和 4-32 $\mu \mathrm{m}$ 的颗粒变化趋势恰恰相反, $>32 \mu \mathrm{m}$ 的颗粒百分含量波动 却趋于平缓,分选性转好, 反映出这段时间内,湖区降水减少,气候较前期干旱,并维持在一个相对较干的水 平上,这是一个水动力较弱的时期. $1130 \mathrm{cal} \mathrm{aBP}$ 至今,该时段的沉积物粒度曲线的变化有一个明显的不同 于其它时段的特征, 即各种颗粒粒径的粒度曲线波动十分频繁, 反映气候在相对干湿的快速转变中波动, 这 段时间经历了中世纪暖期和小冰期两个显著的气候事件, $134-100 \mathrm{~cm}$ (约 $1150-810 \mathrm{cal} \mathrm{aBP}$ ), 正是欧洲人 所称的中世纪暖期 ${ }^{[26]}$, 很明显的是, 在这段时间内粗颗粒含量增加,该区气候较前期湿润,但并不持续,而 到了 $70-58 \mathrm{~cm}$ (约 $450-330 \mathrm{cal} \mathrm{aBP}$ ), 正值历史上的小冰期时期 ${ }^{[27]}$, 此段粗颗粒含量明显减少, 可能是小 冰期气候变化的反映. 58 - $0 \mathrm{~cm}$ (330 $\mathrm{cal} \mathrm{aBP}-$ 至今), 如图 4 中, > $32 \mu \mathrm{m}$ 粗颗粒物质在波动中增加, $<4$ $\mu \mathrm{m}$ 的粘土百分含量频繁波动,一方面反映出降水变化波动较大,较早全新世湿润. 另一方面, 结合年代及 沉积速率, 如图 3 所示, 上部湖相沉积物的沉积速率远远大于下部的沉积速率,这一特征还可能与人类活动 增加有关, 这段时期人类活动显著, 期间湖区周围的过渡旺殖、耕种对流域的影响比较大, 尤其是近几十年 里, 承产养殖及旅游区服务设施的过度兴建, 大片的森林被砍伐, 破坏了原始植被, 水土流失严重 ${ }^{[28]}$, 大量 地表裸露, 降水冲刷地表作用明显增大, 使得粗颗粒汇人入湖河流进人湖泊. 另外, 由于水库的建设, 进行人 为调节水量,很大程度上影响了各粒级颗粒的分布特征.

\section{5 结论}

以上对镜泊湖剖面沉积物粒度特征作了分析,沉积物粒度的变化反映了镜泊湖湖区的干湿变化情况, 可以初步得出以下结论: 早全新世初期 (约 $9300-8540 \mathrm{cal} \mathrm{aBP}$ ), 该地区处于比较干燥的时期. 已有的研究 也指出, 在东北地区, 约 $10000-9000 \mathrm{aBP}$, 气候由前期的湿润转干. 袁绍敏等人对长白山花粉的研究说明了 长白山区在 $9000 \mathrm{aBP}$ 左右, 气候转干 ${ }^{[29]}$, 周昆叔也指出东北地区全新世早期气候偏干 ${ }^{[30]}$, 夏玉梅对三江平 原的花粉资料的研究也表明 $9500-8000 \mathrm{aBP}$ 属于一个增温期, 气候较干 ${ }^{[31]}$, 这与任国玉等通过泥炭、黄土 等的研究结果一致 ${ }^{[32]}$. 进人全新世大暖期 $(8540-3120 \mathrm{cal} \mathrm{aBP})$ 后,前期 $(8540-6350 \mathrm{cal} \mathrm{aBP})$ 气候温暖湿 润, 降水增加, 补给水动力增强. 在东北地区已有的在勤得利 ${ }^{[31]}$ 、孤山屯 ${ }^{[33]}$ 和金川 ${ }^{[34]}$ 等地的花粉曲线, 均 指示当地有效湿度最大的时段变化于 11 000-6 $000 \mathrm{aBP}$, 这与本文研究结果较为一致. 后期 $(6530-3120$ cal aBP) ,气候波动较频繁,出现干湿交替出现的情况.一度出现干旱时期,而后缓慢向湿润期过渡,与张小 
咏 ${ }^{[35]}$ 对辽西北地区近 5000 年的研究得出的 5000-4400 aBP 冷干,4400-2750 aBP 湿润的结果相呼应. 期 间人湖水流的增多与减少在时间上与王苏民等根据现有的湖面波动的资料总结出的湖面下降回升时期较 为一致 ${ }^{[36]}$. 全新世的晚期,3120-1580 cal aBP 较为湿润, 可以与袁绍敏对东北长白山花粉分析结果 ${ }^{[29]}$ 和 王志国对吉林金川泥炭 ${ }^{[37]}$ 的研究结果进行对照. 自 $1580 \mathrm{cal} \mathrm{aBP}$ 以来, 沉积物各粒度参数曲线的变化均比 较频繁,出现干湿交替的气候条件, 不仅与湖区气候及水动力条件有关, 更与人类活动的影响是分不开的. 致谢: 在实验过程中, 得到了夏威岗高级工程师的帮助, 野外钻探采样得到姚书春博士、中科院地球环境研 究所孙千里博士、东北师范大学王升忠教授和东北地理与农业生态研究所邓伟所长等的帮助, 在此表示诚 挚的感谢! 野外采样和论文撰写过程中得到王苏民研究员的悉心指导,谨表感谢!

\section{6 参考文献}

[1] 鹿化暗, 安芷生. 洛川黄土粒度组成的古气候意义. 科学通报, 1997, 42(1) : 67 - 69 .

[2] Giancarlo G B, Nicholas M I. Holocene periodicity in North Atlantic climate and deep-ocean flow south of Iceland. Nature, 1999, 397: $515-517$.

[3] Digerfeldt G, Olsson S, Sandgren P. Reconstruction of lake-level changes in lake Xinias, central Greece, during the last 40000 years. Palaeogeography, Palaeoclimatology, Palaeoecology, 2000, 158: 65 - 82 .

[4] Celina Campell. Late Holocene lake sedimentology and climate change in southern Alberta, Canada. Quaternary Research, 1997, (49) : 96 - 101.

[5] Ann C, Dieffenbacher-Krall, Andrea M N. Late-glacial and Holocene record of lake levels of Mathews Pond and Whitehead Lake, northern Maine, USA. Journal of Paleolimnology, 2005, 34: 283 - 310.

[6] 陈敬安, 万国江, 张峰等. 不同时间尺度下的湖泊沉积物环境记录一一沉积物粒度为例. 中国科 学 (D 辑), 2003, 33(6): $563-568$.

[7] 王君波,朱立平. 藏南沉错沉积物的粒度特征及其古环境意义. 地理科学进展, 2001, 21 (5):459 $-467$.

[8] 陈敬安, 万国江, 徐经意. 洱海沉积物粒度记录与气候干湿变迁. 沉积学报, 2000, 18 (3): 341 -345 .

[9] 李志民, 吕金福, 冷雪天等. 大布苏湖全新世沉积岩芯的粒度特征与湖面波动. 东北师范大学学报 (自 然科学版), $2000, \mathbf{3 2}(2): 117-122$.

[10] 孙千里, 周 杰, 肖举乐. 岱海沉积物粒度特征及其古环境意义. 海洋地质与第四纪地质, 2001, 21 (1) : $93-95$.

[11] 陈敬安, 万国江. 云南程海沉积物粒度研究. 环境科学进展, 1999, 7(4): 76-82.

[12] 刘兴起, 王苏民, 沈 吉. 青海湖 QH-2000 钻孔沉积物粒度组成的古气候古环境意义. 湖泊科学, $2003, \mathbf{1 5}(2)$ : $112-117$.

[13] 陈敬安, 万国江. 洱海近代气候变化的沉积物粒度与同位素记录. 自然科学进展, 2000, 10(3): 253 -259 .

[14] Dearing J A. Sedimentary indicators of lake-level changes in the humid temperate zone: a critical review. Journal of Paleolimnology, 1997, 18(1): $1-14$.

[15] Menking K M, Bischoff J L, Fitzpatrick J A, et al. Climatic/hydrologic oscillations since 155,000 yr B. P. at Owens Lake, California, reflected in abundance and stable isotope composition of sediment carbonate. Quaternary Research, 1997, 48(1): $58-68$.

[16] Bond G, Showers W, Cheseby M, et al. A pervasive millennial scale cycle in North Atlantic Holocene and Glacial climates. Science, 1997, 278: $1257-1266$.

[17] 勒桂云,刘东生. 华北北部全新世降温气候事件与古文化变迁. 科学通报, 2001, 46 (20): 1725 -1730 .

[18] 施雅风, 孔昭宸, 王苏民等. 中国全新世大暖期气候波动与重要事件. 中国科学 ( B 辑 ), 1992, 12 : 
$1300-1307$.

[19] 王相波, 柳玉珍. 镜泊湖莲花水电站联合电力调度研究. 东北水利水电, 1999, (6) : 5-6.

[20] 张盛学, 曾庆云, 王桂礼等. 黑龙江省地理. 哈尔滨: 黑龙江教育出版社, 1987:85-86.

[21] 李岫荣, 李春艳. 镜泊湖 (湖区) 土壤类型及分布规律. 哈尔滨师范大学自然科学学报, 1992, 8 (3) : $95-102$.

[22] 吴敬禄, 王苏民. 若尔盖盆地 $\mathrm{RM}$ 孔 $\delta^{18} \mathrm{O} 、 \delta^{13} \mathrm{C}$ 自生碳酸盐记录所揭示的环境演化特征. 海洋地质与 第四纪地质，1997，17(4): 63-71.

[23] 成都地质分院陕北队编. 沉积岩 (沉积物) 粒度分析及应用. 北京: 地质出版社, 1978 .

[24] Lerman A. Lakes: Chemistry, Geology, Physics. Berlin: Springer-verlag, 1978:79- 83.

[25] 施雅风, 孔昭宸, 王苏民等. 中国全新世大暖期气候与环境的基本特征. 见: 施雅风, 孔昭宸编. 中 国全新世大暖期气候与环境. 北京: 海洋出版社, 1992:1-18.

[26] Hughes M K, Diaz H F. Was there a Medieval Warm Period, and if so, where and when. Climatic Change, 1994, 26: $109-142$.

[27] 王绍武, 叶瑾琳, 龚道溢. 中国小冰期气候研究. 第四纪研究, 1998, (1)：54-56.

[28] 彭瑞琦, 陈 兴等. 镜泊湖旅游区水质状况调查与评价. 中国公共卫生管理, 2001, 17 (3): 239 -241 .

[29] 袁绍敏,孙湘君. 据花粉分析推论东北长白山西麓一万年来的植被与环境. 植物学报, 1990,32(7): $558-567$.

[30］周昆叔，陈硕民，陈承惠等. 中国北方全新统花粉分析与古环境. 见：中国孢粉学会编，第四纪孢粉 分析与古环境. 北京: 科学出版社, 1984: 25-52.

[31] 夏玉梅. 三江平原 12000 年以来植物群和气候变化的初步研究. 地理科学, 1989,8(3): $240-249$.

[32] 任国玉. 中国东北全新世干湿状况的演变. 地质论评, 1999, 45(3): 255-264.

[32] 刘金陵. 长白山孤山屯沼泽地 13000 年以来的植被与气侯变化. 古生物学报, 1989,28(4):240-248.

[34] 孙湘君，袁绍敏. 据花粉资料推断吉林金川地区最近 1 万年的植被演化. 见: 黄土 - 第四纪地质 - 全 球变化,第二集. 北京:科学出版社, $1990: 46-57$.

[35] 张小咏, 李永化, 刘耕年等. 辽西北地区全新世中期以来环境变迁. 海洋地质与第四纪地质,2004,24 (4) : $115-120$.

[36] 王苏民，王富葆. 全新世气候变化的湖泊波动. 见：施雅风，孔昭宸编. 中国全新世大暖期气候与环 境. 北京:海洋出版社, 1992: $146-152$.

[37]王志国. 吉林金川泥炭纤维素稳定碳同位素组成序列与东北季风区五千多年来的环境变迁. 矿物岩 石地球化学通报, 1998, 17(1): 52-54. 